\title{
Editorials
}

\section{Penetrating cardiac injuries in the United Kingdom}

Before 1897 cardiac injuries defied surgical treatment. In that year Rehn successfully repaired a wound of the right ventricle and heralded a new age for surgery. ${ }^{1}$ Since then many factors have brought about an enormous increase in the number of patients with cardiac injuries arriving alive in centres able to deal with them. An increase in civil violence, especially in inner cities; racial disharmony; and specific trouble spots, such as Belfast, increase the incidence of cardiac injuries. Moreover, sophisticated communication networks, rapid evacuation, and immediate resuscitative measures allow many more patients with cardiac wounds to arrive in hospital alive.

In many countries, especially the United States, the free use of hand guns over many years and the willingness of the populace to carry arms have given surgeons there a vast experience in dealing with cardiac wounds of all kinds. The Ben Taub General Hospital Trauma Center in Houston, Texas, for example, deals with $80-100$ penetrating cardiac injuries a year, equally distributed between stab and gunshot wounds (KL Mattox, personal communication, 1982). On the other hand, the United Kingdom thoracic surgical register for $1980^{2}$ reports only 18 operations for cardiac injuries of all kinds.

Sugg et $\mathrm{al}^{3}$ in 1968 reported on a series of 459 penetrating cardiac wounds in Dallas over a nineyear period. Three hundred and seventy-three patients $(81 \%)$ were dead on arrival at hospital. Of these, $80 \%$ had gunshot wounds; whereas over half $(56.6 \%)$ of the 86 patients admitted alive had stab wounds. Even with the advanced emergency medical service systems of the 1980 s, only $40-50 \%$ of patients with penetrating cardiac wounds can be expected to reach hospital alive.

Fortunately, on the United Kingdom mainland stab wounds greatly outnumber gunshot wounds and a greater proportion of all patients with cardiac wounds should reach hospital alive than in the United States. The infrequency of multiple wounds in the UK also gives patients a greater chance of reaching hospital alive. In Northern Ireland, however, in the last seven years nine patients reached hospital alive with cardiac gunshot wounds and 11 with stab wounds (JRP Gibbons, personal communication, 1982). There was one death in each group. This distribution of gunshot and stab wounds is exactly that seen in Houston and the similarity to the latter's death rate attests to the sophisticated evacuation and resuscitation techniques applied in Belfast at the Royal Victoria Hospital.

The principles of management of these patients have been discussed extensively in published reports. ${ }^{34-8}$ Mortality is related to delay in surgery, cerebral damage before relief of tamponade, and the presence of associated injuries, especially of the pulmonary vessels, oesophagus, abdomen, and head and neck. In cases of gunshot wounds the mortality rate also depends on the muzzle velocity of the weapon. High-velocity wounds produce extensive soft-tissue damage and cavitation, whereas lowvelocity wounds may simply cause a puncture and track lesion. Rarely, a bullet embolus may occur if a low-velocity projectile comes to rest in a cardiac chamber or great vessel.

Emphasis has rightly been placed on the efficacy of immediate emergency room thoracotomy in patients apparently dead on arrival if any body warmth or spontaneous respiratory effort is noted. ${ }^{910}$ Dilated pupils, absent pulses, or unrecordable blood pressure are not contraindications to exploration and over $10 \%$ of such patients may survive to leave hospital. Under these extreme circumstances, left anterolateral thoracotomy with relief of tamponade is required initially. Extended across the sternum, this incision gives access to most wounds and requires a minimum of special instruments and skills. In patients not in extremis, emergency room thoracotomy has reduced the mortality of cardiac injuries (in patients admitted alive) from around $60 \%$ to under $20 \% .^{10}$

If the external wound overlies the cardiac silhouette, there is a greater than $60 \%$ chance that the heart has been penetrated, though an entry wound remote from the silhouette-for example, in the abdominal wall or neck-may still be associated with cardiac damage, especially from low-velocity gunshot wounds, where the projectile is easily deflected from its expected path. ${ }^{10}$ Haemodynamic stability should not be assumed to indicate that the heart has not been wounded, and such patients should be managed with extreme caution as sudden catastrophic deterioration, with cardiac tamponade, 
may occur. Clinical assessment, insertion of arterial and central venous monitoring lines, and venous access for rapid transfusion are essential and are best undertaken close to or in an area equipped for immediate thoracotomy. At least 10 units of blood should be cross-matched. A chest radiograph may be obtained, but is not usually of value except to exclude concomitant pneumothorax, haemothorax, or both. The clinical finding of pulsus paradoxus, confirmed on the arterial pressure trace, is highly significant and is a strong indication for early operation.

There is little to support the use of pericardiocentesis in these circumstances. ${ }^{10}$ If the patients are observed in an area prepared for immediate operation its use is unnecessary. Perhaps pericardiocentesis should be performed only to allow transfer of the patient to such an area, or while awaiting instruments or personnel. Pericardiocentesis is by no means easy, however. Failure to aspirate blood may be due to malposition of the needle or to the presence of clot, whereas an apparently succesful aspiration may be of ventricular blood. The procedure may also damage the heart further and may delay the more appropriate expedient of emergency thoracotomy with operative relief of tamponade followed by cardiorrhaphy. The latter has been shown to be associated with substantially fewer deaths than pericardiocentesis alone. ${ }^{10}$

Should immediate thoracotomy for relief of tamponade not be required, alternative incisions may be considered. If the right ventricle is likely to be the injured chamber median sternotomy gives excellent access and is probably superior to a left anterolateral incision extended across to the right side. Sternotomy also gives good access to the right atrium, aorta, and pulmonary artery. For wounds lateral to the nipple, left or right thoracotomy is more appropriate and allows concomitant injuries of other intrathoracic organs to be dealt with.

After cardiac tamponade has been relieved and clot evacuated, internal cardiac massage with digital occlusion of the wound will re-establish cerebral perfusion. This is further enhanced if the descending aorta is intermittently occluded while the blood volume is restored by rapid transfusion. These manoeuvres usually bring about rapid improvement in the patient's condition with restoration of cardiac activity and blood pressure, allowing a margin of safety while the cardiac injury is dealt with. Almost all cardiac stab wounds can be controlled digitally, though a partial occlusion clamp may be of use in injuries such as those of the atrium or great vessels. Traction on a balloon catheter inserted into the wound may be of use if there is tissue loss, or if more than one chamber has been injured. Closure of the cardiac wound should use buttressed sutures, par ticularly in the muscular chambers. ${ }^{8}$ Manoeuvres t $\$$ avoid damage to coronary arteries during suture of cardiac wounds have been reported. ${ }^{4}$

The emergency treatment of patients with wound of coronary arteries remains difficult. Althoug small anterior branches and distal segments of lefe anterior descending and diagonal vessels may be tied off in the young with little chance of significant muscle loss, repair of damaged proximal arteries i⿸广户 essential. Direct end-to-end suture is almost imposs ible. Vein-patch angioplasty may be used anteriorly but coronary bypass using autologous vein may bi necessary. Cardiopulmonary bypass is usualljo required, and this kind of procedure is therefore limited to those centres having such facilities.

To judge by recent experience, patients admitted alive to the Ben Taub Trauma Center in Houstom with a cardiac stab wound and a discernible bloo $\$$ pressure have a $92 \%$ chance of survival; $80 \%$ survi val is reported for those with gunshot wounds (KE Mattox, personal communication, 1982). Althought the presentation, principles of management, and surgical techniques will be the same in the United Kingdom as in the United States, the experience of individual UK centres in dealing with cardia wounds is much smaller. Patients with these injurieg are not necessarily evacuated to the centres be able to deal with them, and the absence of paramed? ical teams is undoubtedly disadvantageous in thes $\vec{\theta}$ cases. As most UK accident and emergency depare

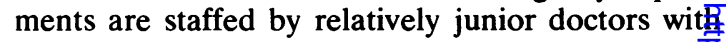
limited surgical experience, unlikely to have the ski or confidence to undertake immediate or emergenct thoracotomy in patients with tamponade, it unlikely that we shall be able to emulate the Houš ton results. The provision of accident ang emergency consultants and a recognised programme of training is a major step forward, but the base position is unlikely to change in the forseeable future, and penetrating cardiac injuries will be mar aged by whatever staff are available. Urgent transfes to a cardiac unit is inappropriate in view of the cataz. strophic deterioration which may occur in appars ently stable patients. Similarly, because cardioput:monary bypass is hardly ever required in dealing with cardiac wounds (JRP Gibbons, personal cones munication, 1982), the lack of such equipment an skills in the receiving unit should be no real barrier to exploration.

In the absence therefore of a cardiothoracic surgit cal unit, those dealing with acute trauma shoulg have no hesitation in instituting life-saving treaf ment in the receiving hospital. Gratifying results cam be achieved with bold intervention and all receivirg surgeons should be aware of the principles outlined 
in dealing with cardiac wounds and.be prepared to undertake emergency treatment, however unlikely survival may seem.

IJ REECE KG DAVIDSON Cardiothoracic Unit Royal Infirmary Glasgow

\section{References}

${ }^{1}$ Rehn L. Uber penetrirende Herzwanden und Herznaht. Arch F Klin Chir 1897;50:315-7.

${ }^{2}$ United Kingdom Thoracic Surgical Register 1980.

${ }^{3}$ Sugg WL, Rea WJ, Ecker RR, Webb WR, Rose EF, Shaw RR. Penetrating wounds of the heart: an analysis of 459 cases. J Thorac Cardiovasc Surg 1968;56:531-45.

4 Sherman MM, Saini VK, Yarnoz MD, Ramp J, Williams
LF, Bereer RL. Management of penetrating heart wounds. Am J Surg 1978;135:553-8.

${ }^{5}$ Beall AC, Diethrich EB, Crawford H, Cooley DA, De Bakey ME. Surgical management of penetrating cardiac injuries. Am J Surg 1966;112:686-95.

- Maynard ADL, Cordice JW, Naclerio EA. Penetrating wounds of the heart. A report of 81 cases. Surg Gynec Obstet 1952;94:605-14.

${ }^{7}$ Naclerio EA. Penetrating wounds of the heart. Experience with 249 patients. Dis Chest 1964;46:1-11.

${ }^{8}$ Evans J, Gray LA, Rayner A, Fulton RL. Principles for the management of penetrating cardiac wounds. Ann Surg 1979;189:777-84.

${ }^{9}$ Rohman M. Emergency room thoracotomy for the resuscitation of patients with "fatal" penetrating injuries of the heart. Ann Thorac Surg 1981;32:37785.

10 DeGennaro VA, Bonfils-Roberts EA, Ching N, Nealon TF. Aggressive management of potential penetrating cardiac injuries. J Thorac Cardiovasc Surg 1980; 79:833-7. 